\title{
ESTUDO HIDROGEOLÓGICO DA CIDADE DE CURITIBA/PR: PRINCIPAIS CARACTERÍSTICAS DAS ÁGUAS SUBTERRÂNEAS
}

\author{
Larissa Oliveira Paulista ${ }^{1}$; Pedro Henrique Presumido ${ }^{2}$; IsabelaMoreira ${ }^{3}$; Luciana Ferreira de \\ Camargo Duarte ${ }^{4}$; Caroline Hatada de Lima ${ }^{5} \&$ Maurício Moreira dos Santos 6
}

\begin{abstract}
Resumo - As águas subterrâneas têm um papel relevante para o abastecimento humano. Na cidade de Curitiba-PR mais de 400.000 mil habitantes são abastecidos diariamente pelos sistemas aquíferos Cárstico (Karst), Cristalino e Guabirotuba. À medida que aumenta a demanda de água pela população, a necessidade de estudos que avaliem os processos de gestão e monitoramento da qualidade das águas subterrâneas ganham importância. O estudo teve como objetivo analisar a classificação química das águas subterrâneas de Curitiba-PR e calcular estimativas de potencialidade hidráulica. Foi realizado o levantamento de um do banco de dados de poços tubulares que exploram às águas subterrâneas na região de estudo disponibilizados pelo Sistema de Informação Geográfica de Águas Subterrâneas (SIAGAS), a fim de relacionar as características hidroquímicas dos diferentes aquíferos e seu contexto geológico regional. Para o estudo do balanço e classificação hidroquímica foi utilizado o software livre Qualigraf. O diagrama Piper e diagramas de Stiff evidenciou predominância de águas Bicarbonatadas Cálcicas ou Magnesianas e Bicarbonatadas Sódicas, resultados esses coerentes com as características geológicas da região estudada. Alguns parâmetros como fluoreto, nitrato e ferro foram encontrados em níveis acima dos permitidos pela legislação, podendo indicar contaminação antrópica. Já a vazão específica calculada ficou, predominantemente, entre 0,1 a $0,5 \mathrm{~m}^{3} / \mathrm{h} / \mathrm{m}$.
\end{abstract}

\footnotetext{
${ }^{1}$ Departamento Acadêmico de Ambiental, Universidade Tecnológica Federal do Paraná, Avenida dos Pioneiros, 3131 - 8636-370, Londrina - Paraná, Brasil, e-mail: larissa-paulista@ hotmail.com.

${ }^{2}$ Departamento Acadêmico de Ambiental, Universidade Tecnológica Federal do Paraná, Avenida dos Pioneiros, 3131 - 8636-370, Londrina - Paraná, Brasil, e-mail: pedrohpresumido@gmail.com.

${ }^{3}$ Departamento Acadêmico de Ambiental, Universidade Tecnológica Federal do Paraná, Avenida dos Pioneiros, 3131 - 8636-370, Londrina - Paraná, Brasil, e-mail: Isabela.moreira@ hotmail.com.

${ }^{4}$ Departamento Acadêmico de Ambiental, Universidade Tecnológica Federal do Paraná, Avenida dos Pioneiros, 3131 - 8636-370, Londrina - Paraná, Brasil, e-mail: lucianaduarte@alunos.utfpr.edu.br.

${ }_{5}^{5}$ Departamento Acadêmico de Ambiental, Universidade Tecnológica Federal do Paraná, Avenida dos Pioneiros, 3131 - 8636-370, Londrina - Paraná, Brasil, e-mail: carolinelima@alunos.utfpr.edu.br.

${ }^{6}$ Departamento Acadêmico de Ambiental, Universidade Tecnológica Federal do Paraná, Avenida dos Pioneiros, 3131 - 8636-370, Londrina - Paraná, Brasil, e-mail: mmsantos@utfpr.edu.br.
} 
Abstract - Groundwater plays a key role in water supply for human consumption. In Curitiba city, a population of more than 400,000 thousand people is supplied by groundwater coming from the Karst Aquifer, the Crystalline Basement and Guabirotuba Aquifer. As water demand rises, the need for studies and knowledge related to groundwater management and monitoring increases. This paper aims to analyze the groundwater chemical classification and estimate the hydraulic potential in the region of Curitiba city. In order to achieve this goal, data regarding the operating wells in Curitiba was collected from the Groundwater Geographic Information System (SIAGAS) to link the water chemical characteristics of each aquifer to its geological aspects. The software Qualigraf was used to carry out the ion balance and to chemically classify the water. Piper's and Stiff's Diagrams have indicated the prevalence of Calcic or Magnesian Bicarbonated and Sodic Bicarbonated waters. These results are consistent with the geological characteristics of the hydrographic basin of the city. Some parameters such as florine, iron and nitrate presented higher concentration than allowed by law, which may indicate a leakage of domestic or industrial wastewater. The calculated specific groundwater flow dominant in Curitiba city is between 0.1 and $0.5 \mathrm{~m} 3 / \mathrm{h} / \mathrm{m}$.

Palavras-Chave - Diagrama de Piper; Diagrama de Stiff; Qualidade da água subterrânea.

\section{1 - INTRODUÇÃO}

As águas naturais contêm diversos elementos e substâncias necessários aos organismos vivos, além de ser fundamental para o desenvolvimento de muitas atividades importantes na nossa sociedade (DI BERNARDO; DANTAS, 2005). A grande maioria das reações, interações tanto física, química ou biológica dependem da qualidade e da quantidade da água. As águas superficiais, por serem visíveis, apresentam à muitas pessoas que os rios, barragens e lagos possuem maior fonte de atendimento da necessidade de água do homem. Porém, mais de 97\% da água doce disponível na Terra, encontra-se no subsolo (águas subterrâneas) e apenas $3 \%$ da água potável são disponibilizados por águas superficiais (FEITOSA; MANOEL FILHO, 2000).

A utilização das águas subterrâneas ocorreu muito antes da compreensão da sua origem, ocorrência e dinamismo. As escavações e perfurações no subsolo para ocorrência de água perdem-se num tempo anterior ao início da civilização (MACHADO, 2005). No Brasil, mais da metade dos municípios utilizam parcialmente ou totalmente águas subterrâneas (IBGE, 2000). Segundo o Ministério do Meio Ambiente (2007), as cidades Ribeirão Preto (SP), Maceió (AL), Mossoró (RN) e Manaus (AM), utilizam todas as suas necessidades hídricas utilizando esse tipo de abastecimento. 
Além de atender a população, as águas subterrâneas também são utilizadas nas indústrias, na agricultura na forma de irrigação e para lazer.

A água doce não é uniformemente distribuída pela superfície do planeta, com isso há a ocorrência de regiões com abundância e outras com extrema escassez. O Brasil, segundo dados da ONU, detém cerca de 13,3\% de toda Reserva Hídrica da Terra, com 180.000 m³/s, o que representa uma disponibilidade hídrica de cerca de $47.000 \mathrm{~m}^{3} / \mathrm{habitante} / \mathrm{ano}$ (ABAS, 2006).

Com o aumento da necessidade de água pela população os números de poços perfurados também seguem esse aumento. De acordo com o SIAGAS, o número de poços cadastrados no Brasil aumento em 56,5\% entre 2008 e 2013 (ANA, 2013).

Os principais aquíferos que contribuem para o abastecimento em Curitiba/PR são: Aquífero Karst, que é utilizado para abastecimento público com população abastecida de 185.515 e volume de produção de 9.028.153 m³/ano; Sistema Aquífero Cristalino e Sistema Aquífero Guabirotuba que são utilizados principalmente para abastecimento de condomínios e serviços em geral. Esses dois últimos possuem população abastecida de 76.000 e 178.800, respectivamente, e volume de produção de $5.733 .234 \mathrm{~m}^{3} /$ ano e $12.600 .000 \mathrm{~m}^{3}$ /ano, respectivamente (HINDI, et al, 2002).

O presente trabalhou buscou avaliar as principais características físico-químicas das águas subterrâneas no município de Curitiba/PR e alguns dados de produção e potencialidade hidráulica.

\section{2 - OBJETIVOS}

O objetivo principal do presente artigo é de apresentar a classificação hidroquímica dos sistemas aquíferos na região de Curitiba-PR e correlacionar com às características geológicas regionais, além disso será apresentado cálculo de potencialidades hidráulica para diferentes sistemas aquíferos e análise de alguns parâmetros químicos quanto a qualidade da água consumida pela população.

\section{3 - METODOLOGIA}

Para a avaliação hidrogeológica dos poços tubulares profundos da cidade de Curitiba/PR foi realizado um levantamento de dados utilizando o Sistema de Informações de Águas Subterrâneas (SIAGAS) gerenciado pelo Serviço Geológico do Brasil - CPRM. O levantamento permitiu a criação de um amplo banco de dados para o desenvolvimento do estudo hidroquímico, da qualidade da água subterrânea, análise dos perfis descritivos geológico dos poços tubulares na região de estudo e análise de produção e vazão das águas subterrâneas. 
Para o estudo hidroquímico foram analisados 14 poços da região. Foi utilizado o software Qualigraf (FUNCEME, 2014) que foi responsável pela construção de diagramas hidroquímicos e para realizar o balanço iônico dos dados. Para avaliação da classificação dos íons principais utilizou-se o diagrama de Piper e diagramas de Stiff. Os principais dados levantados para essa etapa foram: $\mathrm{Na}^{+}, \mathrm{K}^{+}, \mathrm{Ca}^{+}, \mathrm{Mg}^{+}, \mathrm{Cl}^{-}, \mathrm{CO}^{-}, \mathrm{HCO}^{-}, \mathrm{SO}^{-}$, condutividade elétrica, $\mathrm{pH}$, turbidez, resíduos sólidos e nitrogênio total.

A qualidade das águas subterrâneas analisadas foi comparada com os parâmetros exigidos pela Portaria $n^{\circ}$ 2.914, de 12 de dezembro de 2011 (BRASIL, 2011), que dispõe sobre os procedimentos de controle e de vigilância da qualidade da água para consumo humano e seu padrão de potabilidade.

Com relação à análise da produção das águas subterrâneas, foram utilizados todos os dados disponíveis no SIAGAS. A produção de águas subterrâneas está ligada a quantidade de água que pode ser retirada para consumo humano. Foi calculada a vazão total, vazão média e mediana, bem como a vazão específica dos poços, e esses resultados foram apresentados de forma geral e separados por formação geológica.

\section{4 - RESULTADOS E DISCUSSÃO}

\section{1 - Diagrama de Piper}

Para o balanço de íons foram utilizados 14 poços tubulares de abastecimento, os quais estão localizados conforme a Figura 1. 


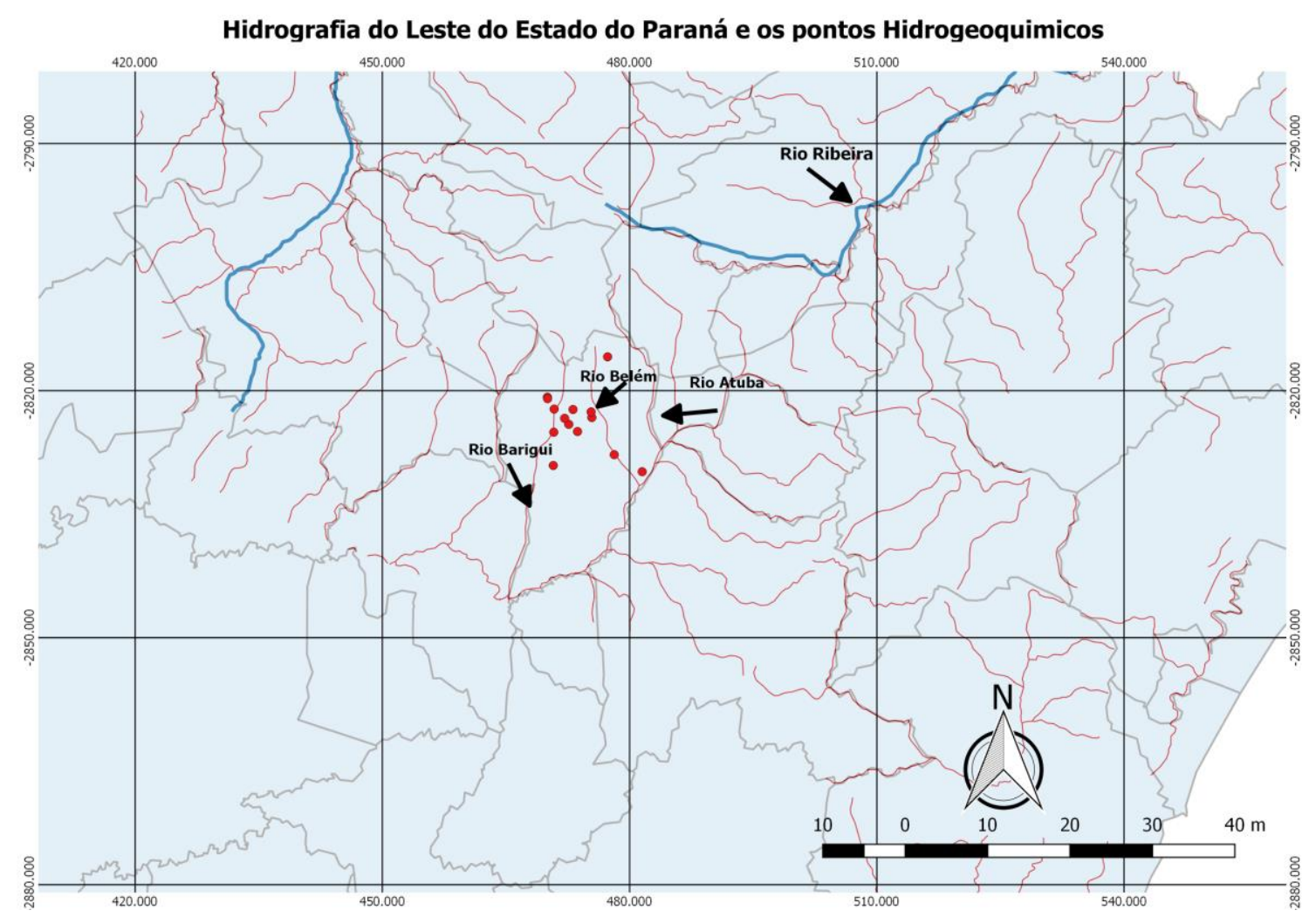

Figura 1 - Localização dos poços tubulares onde foram coletados os dados para avaliação hidroquímica na região de estudo.

O diagrama de Piper é frequentemente utilizado para a comparação e classificação de distintos grupos de águas quanto aos íons presentes e dominantes em cálcica, cloretada, bicarbonatada, sódica, magnesiana, sulfatada ou mista (FUNCEME, 2014).

O diagrama de Piper classificou as águas como: Águas Bicarbonatadas Cálcicas ou Magnesianas e Águas Bicarbonatadas Sódicas. Sendo que, os ânions presentes são bicarbonato e o cátion mais abundante é o cálcio. Dessa forma, de uma maneira geral, as águas subterrâneas deste estudo podem ser classificadas como Águas Bicarbonatadas Cálcicas ou Magnesianas (Figura 2). 


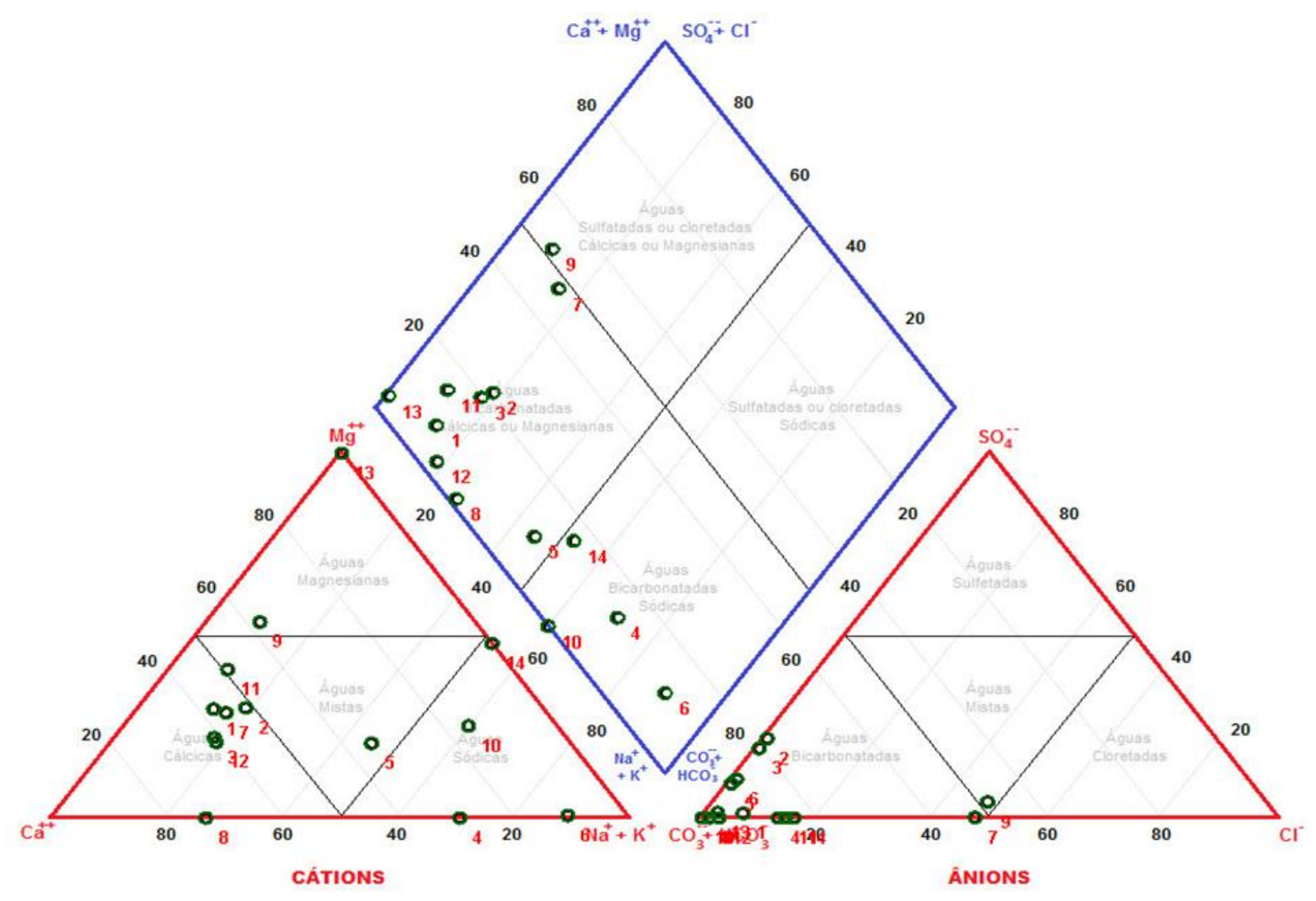

Figura 2 - Diagrama de Piper para os poços analisados.

Para o consumo humano, as águas não apresentam restrições quanto aos elementos em análise. O consumo industrial pode apresentar restrições devido, principalmente, à composição cálcica e magnesiana, que pode causar incrustações ou entupir tubulações se a dureza for relativamente alta (SILVA et al., 2011).

\section{2 - Diagrama de Stiff}

No diagrama de Stiff, as concentrações iônicas são expressas em meg/L e representadas sobre linhas paralelas horizontais. No lado direito do gráfico, ficam os ânions e no lado esquerdo estão os cátions, resultando assim, em uma figura geométrica característica para cada amostra de água analisada. Esse tipo de gráfico facilita a visualização e comparação dos resultados (INVERNIZZI, 2001).

Na Figura 3 são mostrados os diagramas de Stiff elaborados para os 14 pontos de amostras. Esses diagramas foram utilizados para facilitar a comparação entre as amostras. 

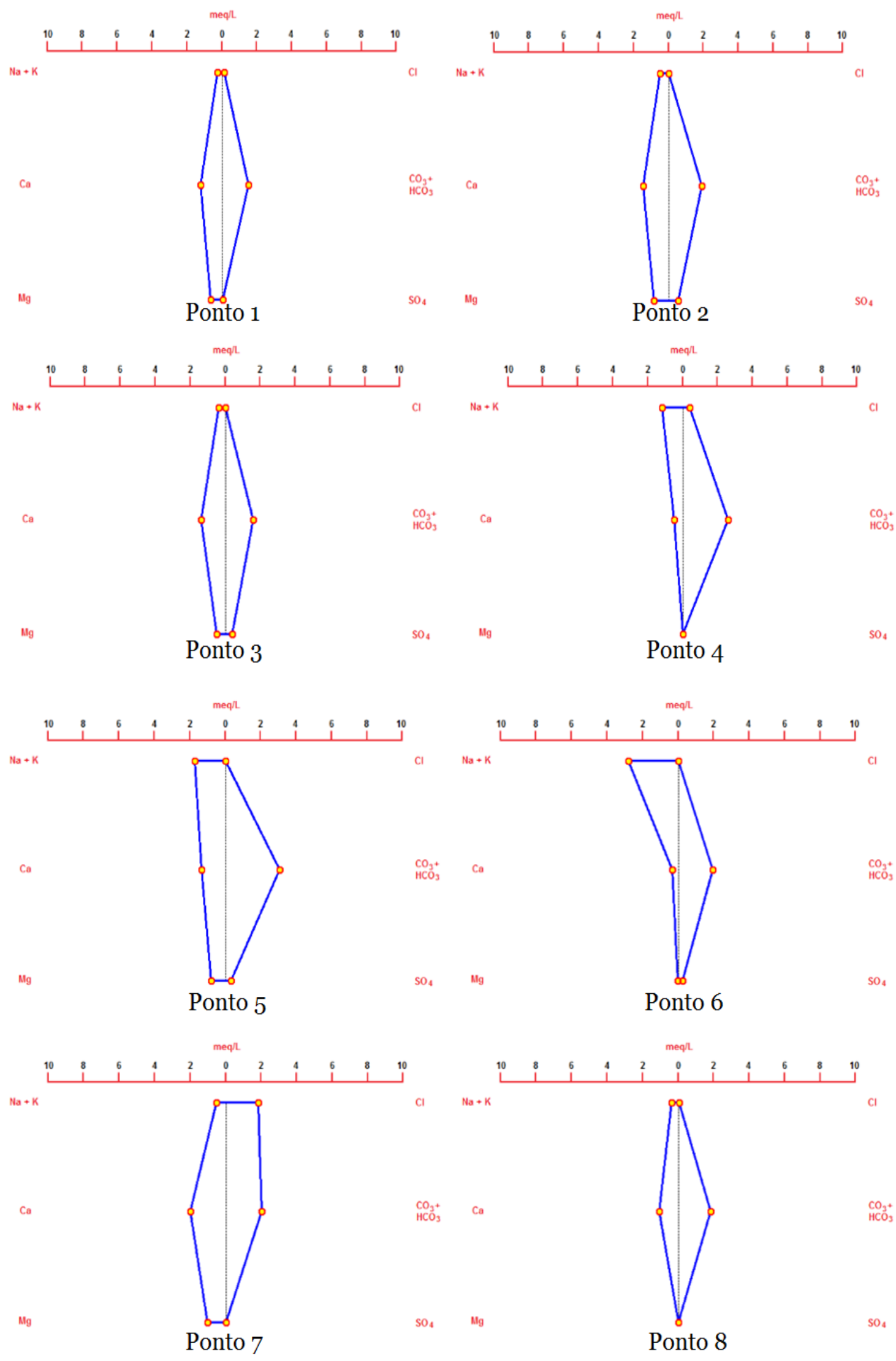

Figura 3 - Diagramas de Stiff construídos para os 14 pontos amostrados. 

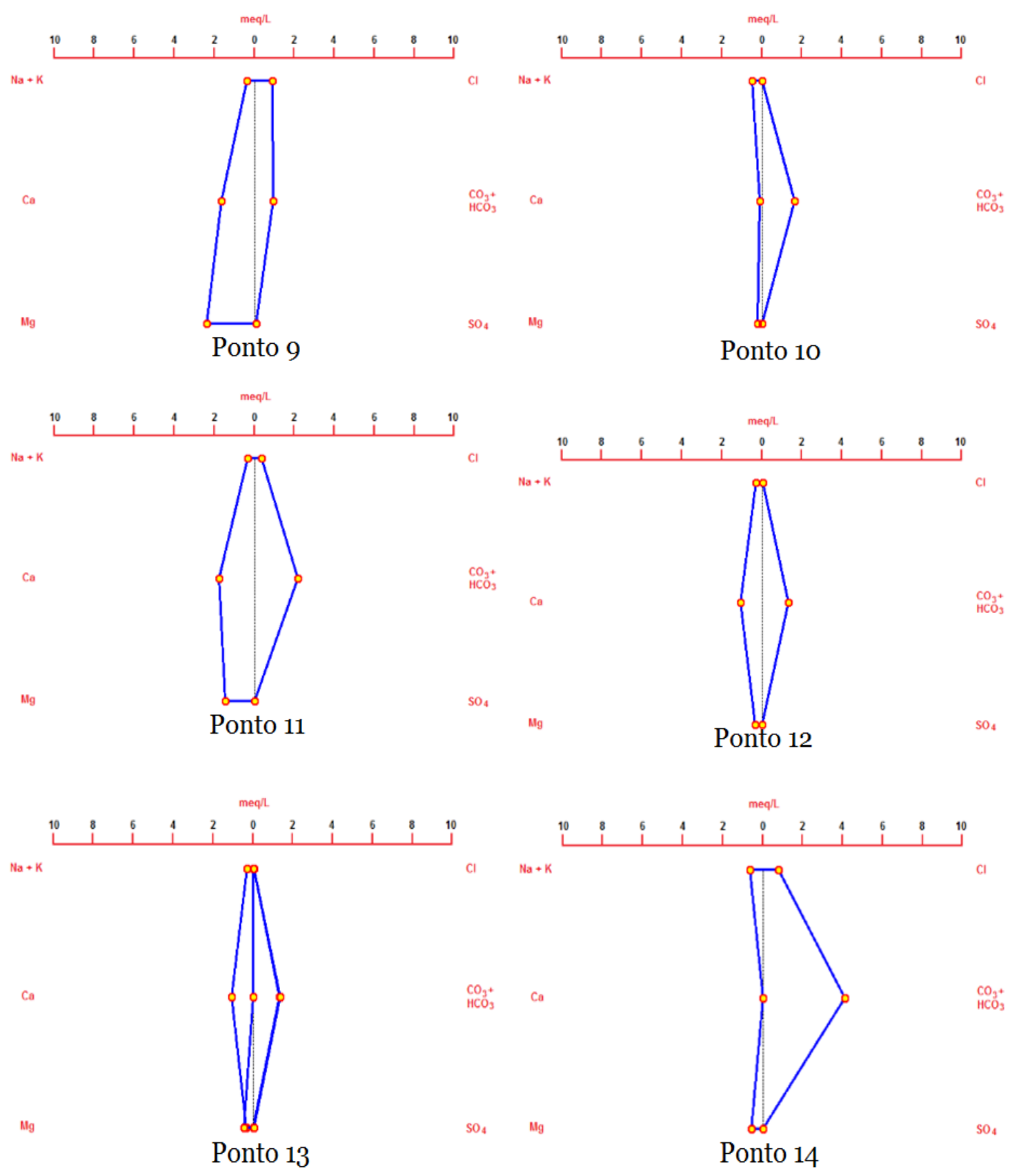

Continuação Figura 3 - Diagramas de Stiff construídos para os 14 pontos amostrados.

As variedades de formas dos polígonos e tamanhos dos modelos gerados, correspondem às características de determinadas águas e permitem a classificação e a correlação dos resultados de suas análises químicas.

Os pontos observados mostram uma variação entre os resultados, porém pode-se notar a presença de íons magnésios e bicabornatados, corroborando o exposto pelo Diagrama de Piper. Esses dados podem ser explicados pelo domínio geológico regional da cidade de Curitiba/PR, onde há predomínio de rochas carbonáticas na área de estudo e são intensamente carstificadas, influenciando assim, nas características das águas subterrâneas (FILHO et al., 2002). 


\section{3 - Qualidade da água subterrânea}

Para análise da qualidade da água foram utilizados 10 poços tubulares, os quais estão localizados conforme a Figura 4.

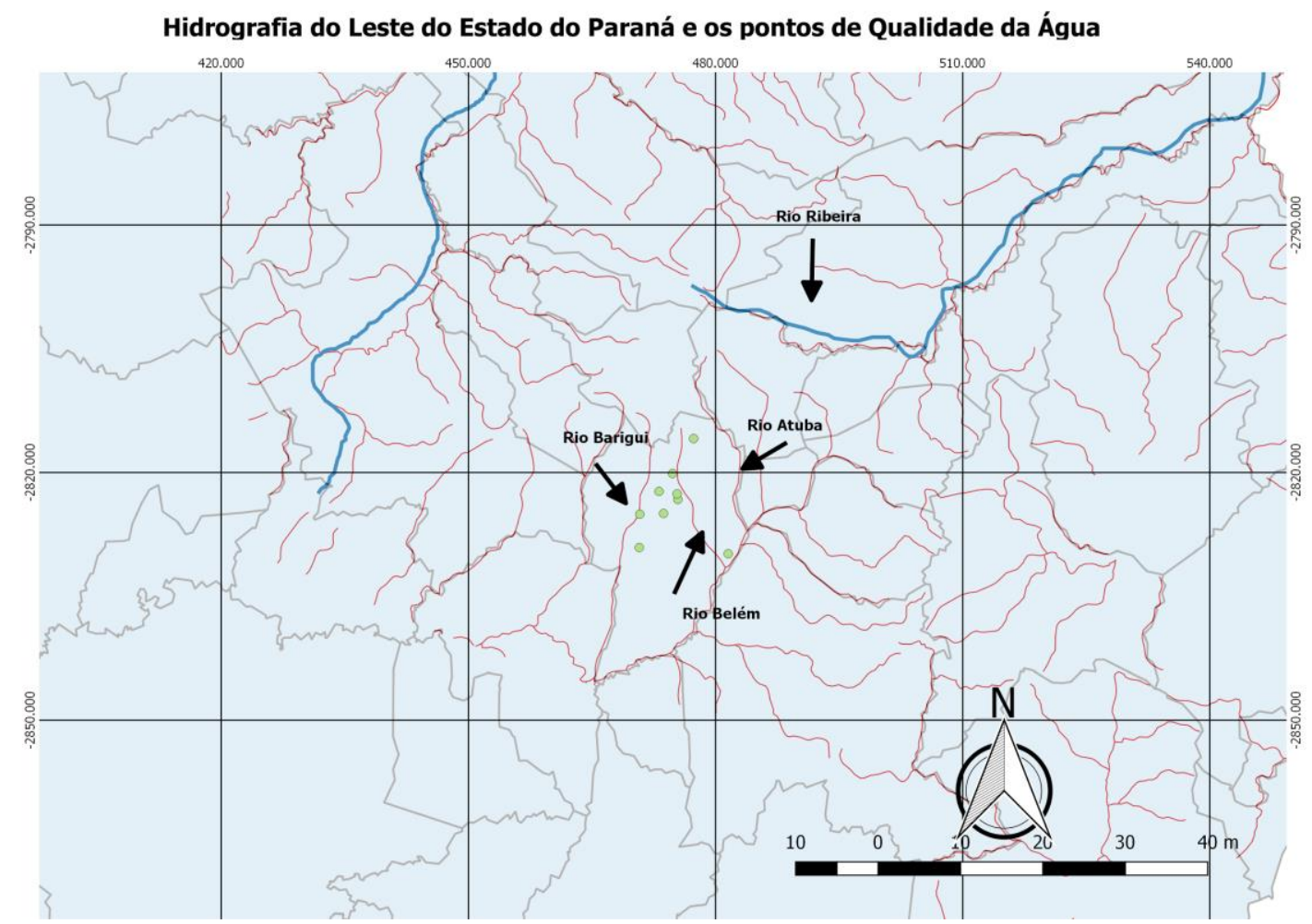

Figura 4 - Localização dos pontos para análise da qualidade da água.

Segundo o Instituto das Águas (2010), o magnésio presente no aquífero Guabirotuba variam de 0,31 a 35,47 mg/L. Percebe-se que o excesso de magnésio, também encontrado no Diagrama de Piper e Stiff, é presente em quase todos os pontos analisado (Tabela 1). Isso se dá pelo tipo de formação geológica, no qual o excesso de magnésio no solo é carreado até as águas subterrâneas.

Aquíferos são formações geológicas subterrâneas capazes de armazenar água, por isso a geologia define os tipos de aquíferos explorados e influencia na constituição química da água (PINTO-COELHO; HAVENS, 2015).

Há alguns pontos nos quais há ocorrências pontuais de contaminação, nas quais apresentam valores superiores a Portaria 2.914/11 (Tabela 1). Uma delas é o excesso de fluoretos encontrado na Vila Izabel. Quando o nível de fluoretos ultrapassa 1,5 mg/L causa manchas brancas nos dentes. Outro problema é seu poder acumulativo, pois $50 \%$ do fluoreto ingerido é excretado e o restante fica 
nos ossos. Além disso, é uma substância biologicamente ativa que interfere nos ligamentos de hidrogênio e na estrutura de proteínas e ácidos nucléicos (NETTO et al, 2004).

Outra alteração observada (Tabela 1) são os níveis de nitrato encontrados na: Uberba, Cidade Industrial de Curitiba (CIC) e Bigorrilho. A infiltração de efluentes domésticos, por exemplo, pode estar relacionada com a presença de nitrato nas águas subterrâneas (ESTUDO DE IMPACTO AMBIENTAL DA LINHA AZUL, 2010). Em concentrações superiores a $10 \mathrm{mg} / \mathrm{L}$ o nitrato gera maiores riscos a crianças com idade inferior a seis meses, o qual pode causar a "síndrome do bebê azul”, nitrosaminas cancerígenas ou até mesmo ser fatal (QUEIROZ, 2004).

E por fim, níveis de ferro também na Cidade Industrial de Curitiba (CIC). O ferro não é um parâmetro de toxicidade, porém a sua presença na água pode causar problemas estéticos como sabor ruim e cor quando há sua oxidação. Além disso, sua presença em sistemas de tratamento reduz a eficiência dos filtros e pré-filtros (OLIVEIRA, 2003).

Um estudo realizado nos aquíferos do Embasamento Cristalino e Guabirotuba indica que, em ambos, há algumas amostras com teores de íon fluoreto, íon nitrato e o ferro total acima do limite de potabilidade. A infiltração de efluentes domésticos, por exemplo, pode estar relacionada com a presença de nitrato nas águas subterrâneas (ESTUDO DE IMPACTO AMBIENTAL DA LINHA AZUL, 2010).

Tabela 1 - Comparação entre os padrões da Portaria 2.914/2011 com os poços analisados em relação à qualidade

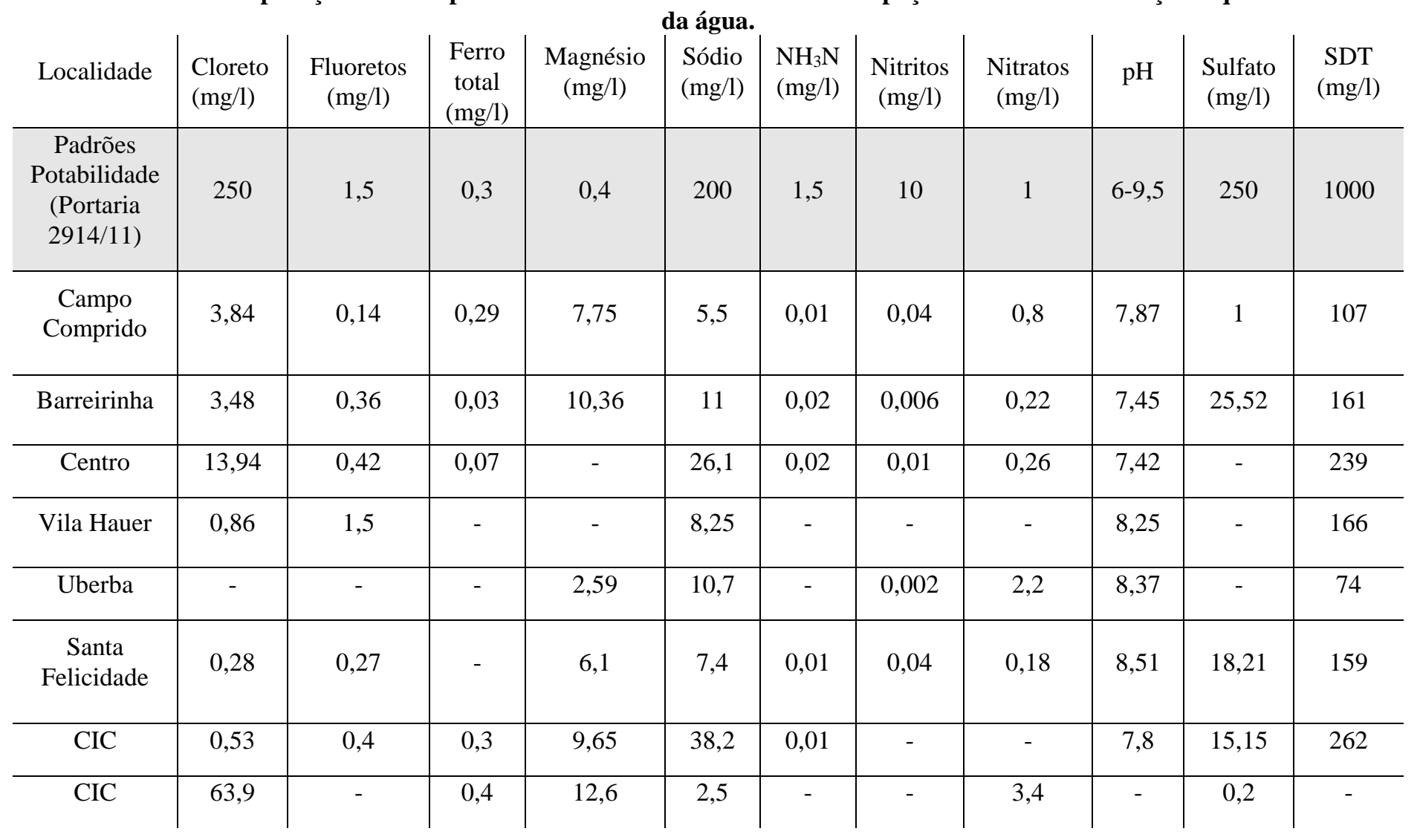




\begin{tabular}{c|c|c|c|c|c|c|c|c|c|c|c} 
Bigorrilho & 32 & 0,1 & - & 29,2 & 8,5 & 0,01 & 0,07 & 9,96 & 8,4 & 4 & 374 \\
\hline Vila Izabel & 0,56 & 2,5 & 0,1 & 0,24 & 64 & - & - & - & 7,27 & 11 & 200
\end{tabular}

\section{4 - Produção total}

Os poços tubulares utilizados para avaliação da produção hidráulica estão identificados na Figura 5. Para a produção total, foram levados em conta o valor de vazão de estabilização cadastrados nos poços encontrados SIAGAS que apresentavam dados necessários aos cálculos e estimativas a seguir.

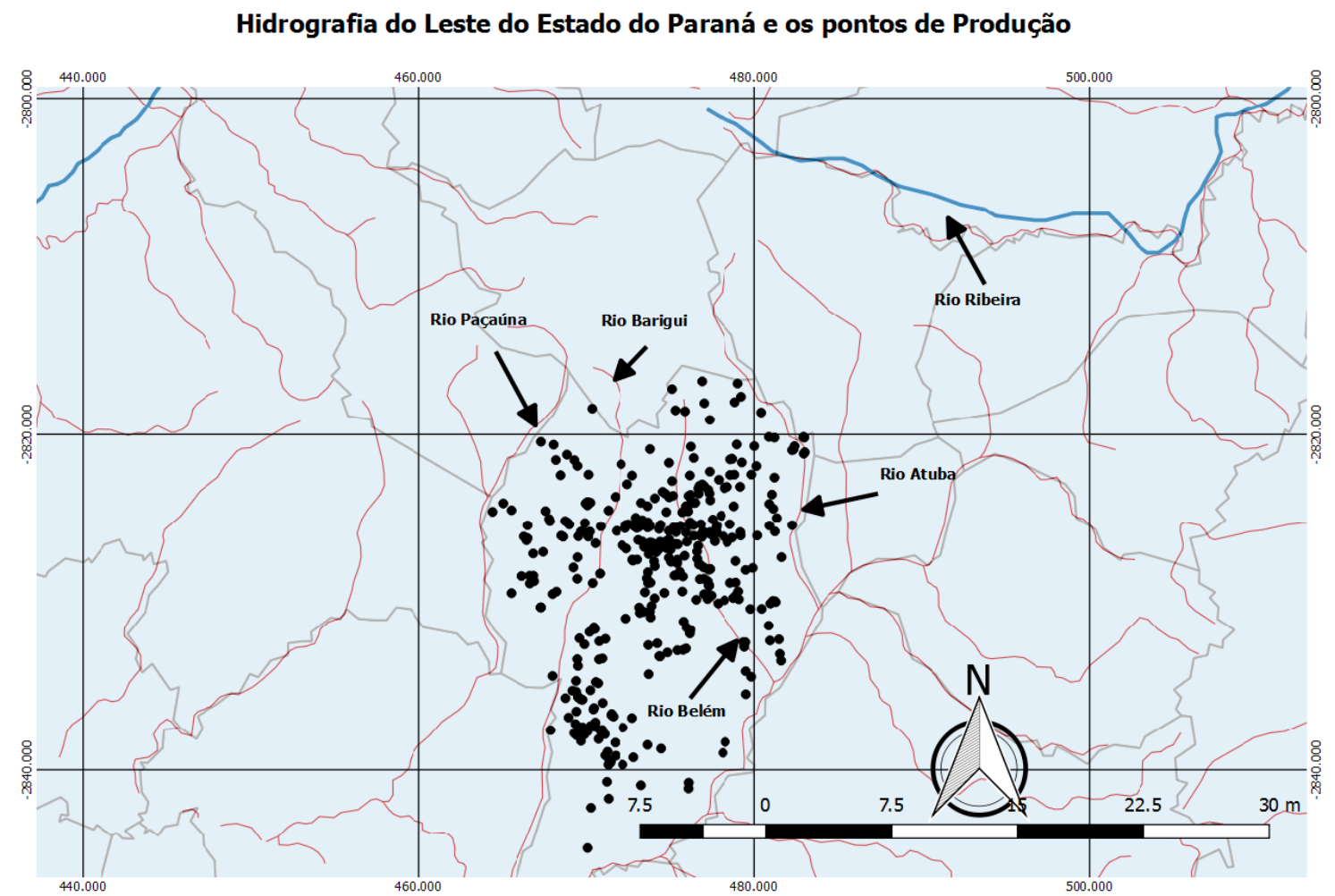

Figura 5 - Localização dos pontos para análise da produção total.

A vazão total dos poços registrados em Curitiba, considerando todos os dados disponíveis no SIAGAS, corresponde à $2673,48 \mathrm{~m}^{3} / \mathrm{h}$, com média de $6,8 \mathrm{~m}^{3} / \mathrm{h}$ por poço e mediana de $4,2 \mathrm{~m} 3 / \mathrm{h}$.

Em termos de produção, a formação Pré-Cambriano se mostrou a mais representativa para a região de Curitiba. Dos 393 poços com dados de produção disponíveis, 265 são contemplados pela formação Pré-Cambriana. Conforme mostrado na Figura 6, A vazão específica total de Curitiba é fortemente influenciada pelos poços da formação Pré-Cambriana. 


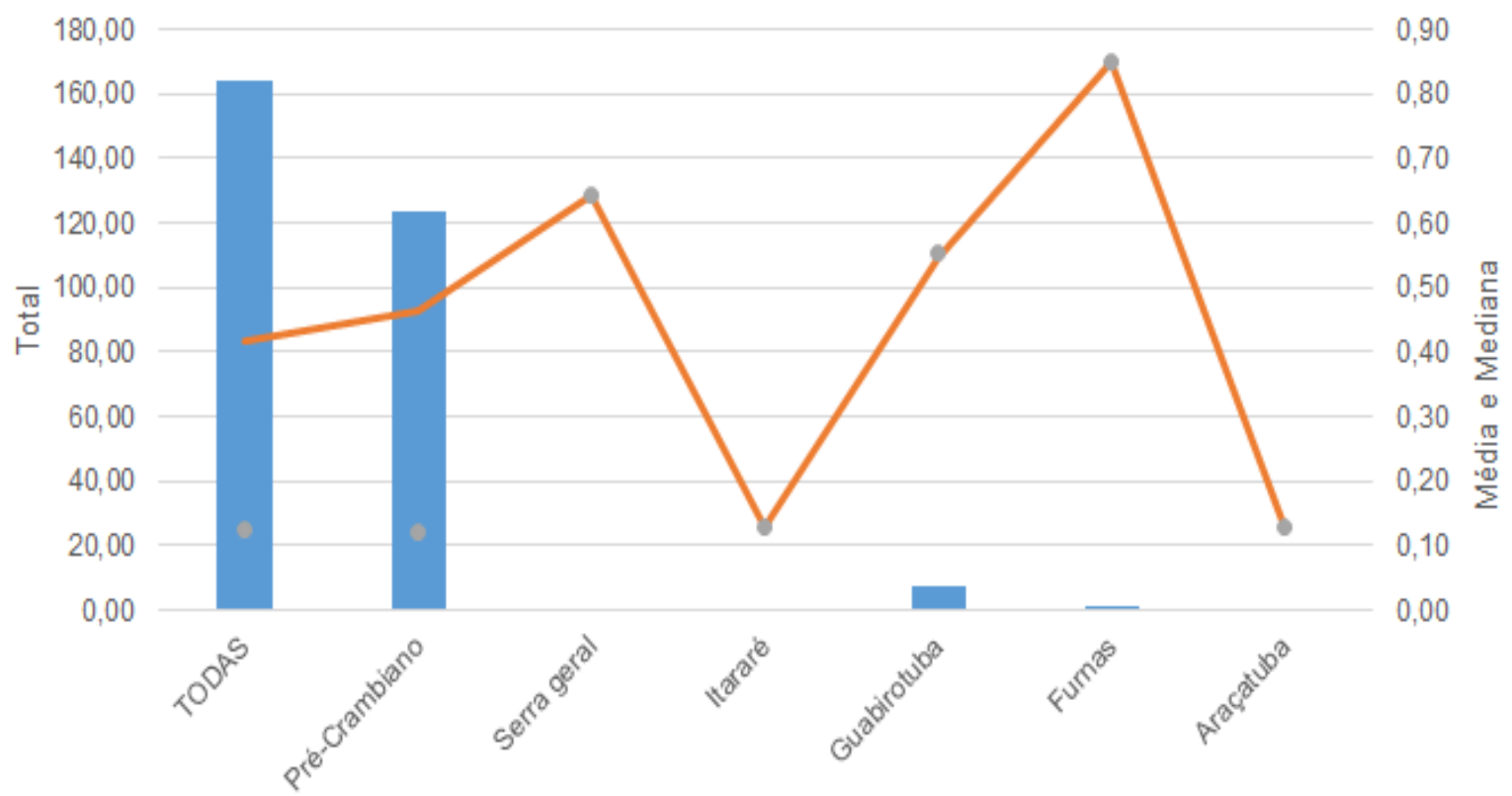

Título do Eixo

- Total Média - Mediana

Figura 6 - Vazão específica total, média e mediana das formações geológicas informadas pelo SIAGAS para Curitiba/PR.

É possível observar que a maioria dos poços apresenta vazão específica entre 0,1 e $0,50 \mathrm{~m}^{3} / \mathrm{h} / \mathrm{m}$, representando $40,0 \%$ dos poços monitorados (Figura 7).

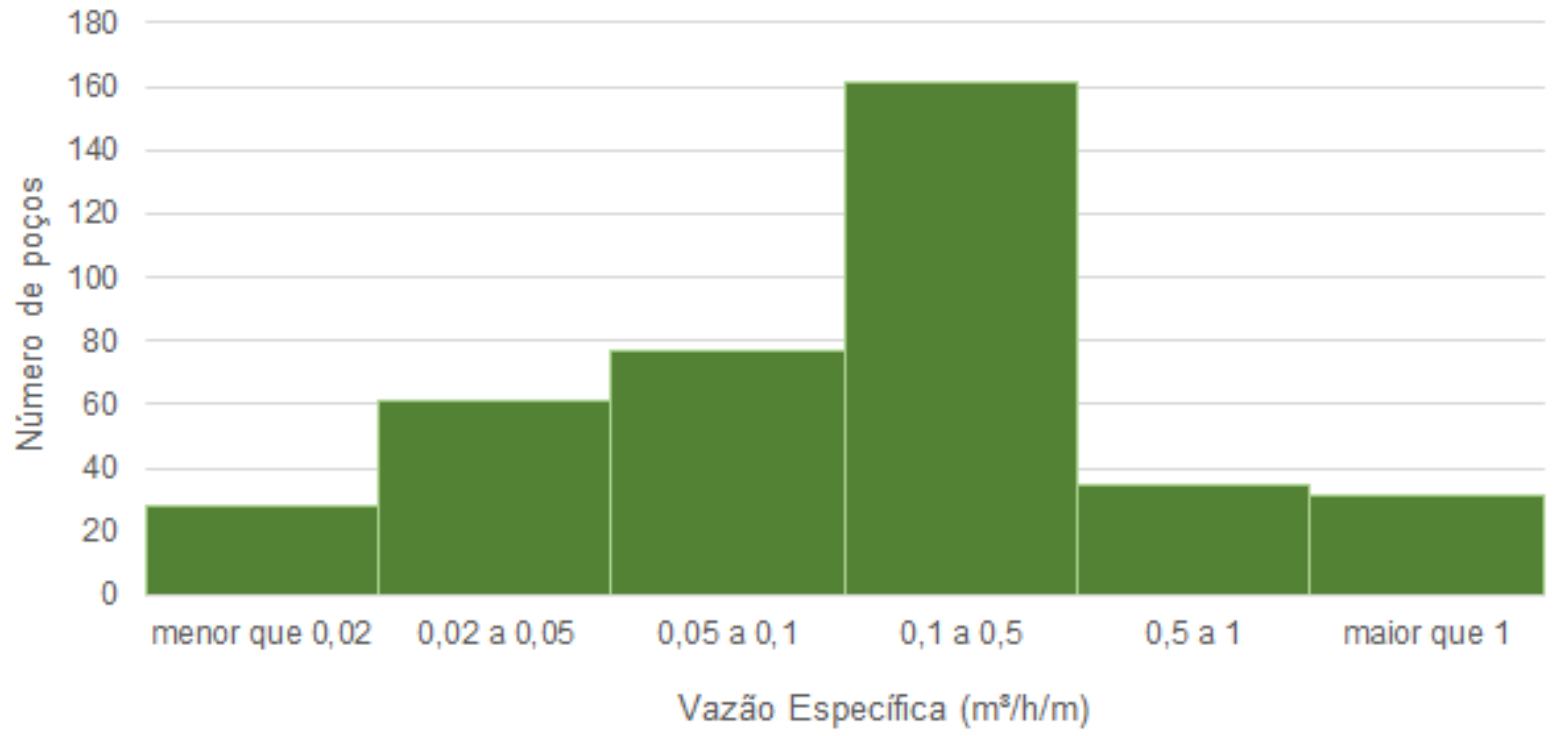

Figura 7 - Histograma de vazão específica dos poços estudados na região de Curitiba/PR.

\section{5 - CONCLUSÕES}

Ambos os diagramas de Piper e de Stiff apontaram para uma predominância de carbonatos e bicarbonatos nas águas subterrâneas estudadas. O diagrama de Piper classificou as águas como 
Bicarbonatadas Cálcicas ou Magnesianas e Bicarbonatadas Sódicas, sendo o cálcio o cátion mais abundante. A classificação obtida pelo diagrama de Piper reflete as características geológicas da bacia hidrográfica de Curitiba/PR, composta, predominantemente, por rochas carbonáticas e carstificadas.

Os parâmetros que apresentaram concentrações superiores ao estabelecido pela Portaria $n^{\circ}$ 2.914/11 do Ministério da Saúde são: fluoreto, nitrato e ferro. Essas alterações podem estar relacionadas com a infiltração de efluentes domésticos ou industriais no solo.

Com relação à produção, os dados disponíveis no SIAGAS para Curitiba apontam para uma vazão total de $2673,48 \mathrm{~m}^{3} / \mathrm{h}$, com média de $6,8 \mathrm{~m}^{3} / \mathrm{h}$ por poço e mediana de $4,2 \mathrm{~m} 3 / \mathrm{h}$. A maior parte dos poços estão compreendidos na região caracterizada pela formação do Pré-Cambriano, o qual abarca 265 dos 393 poços estudados. A vazão específica predominante em Curitiba (40\% dos poços) varia entre 0.1 e $0.5 \mathrm{~m} / \mathrm{h} / \mathrm{m}$, representando $40,0 \%$ dos poços monitorados.

Importante destacar que o SIAGAS apresenta muitas lacunas nas informações dos poços tubulares, o que dificulta um estudo mais robusto da qualidade das águas subterrâneas. Ainda assim, é possível filtrar os dados e obter informações de extrema importância para o estudo hidrogeológico de uma região de interesse, como é o caso de Curitiba.

\section{6 - REFERÊNCIAS BIBLIOGRÁFICAS}

ABAS - Associação Brasileira de Águas Subterrâneas. Orientações para a utilização de águas subterrâneas no estado de São Paulo. São Paulo, 2005.

ANA - Agência Nacional de Águas. Conjuntura dos recursos hídricos no Brasil. Brasília: ANA, 2013, 432p.

BRASIL, Ministério da Saúde. Portaria n. o 2.914, de 12 de dezembro de 2011. Dispõe sobre normas de potabilidade de água para o consumo humano. Brasília: SVS, 2011.

DI BERNARDO, Luiz; DANTAS, Angela D. B. Métodos e técnicas de tratamento de Água. Vol. 1.

2. Ed. RiMa Editora, São Carlos, 2005.

ESTUDO DE IMPACTO AMBIENTAL DA LINHA AZUL. Sistema de Metrô de Curitiba. Prefeitura Municipal de Curitiba, 2010. 
FEITOSA, F.A.C.; MANOEL FILHO, J. Hidrogeologia - Conceitos e Aplicações. 2a Ed. Fortaleza: CPRM/REFO, Labhid-UFPE, 2000.

FILHO, E.R.; POLIDORO, G.; HARUM, T.; LISBOA, A.A.; RIBAS, A.; ZOJER, H. Projeto Carste: Relatório conclusivo final. Instituto de Hidrogeologia e Geotermia. Curitiba, 2002.

FUNCEME - FUNDAÇÃO CEARENSE DE METEROLOGIA E RECURSOS HÍDRICOS. Qualigraf: Software para interpretação de análises físico-químicas. Governo do Estado do Ceará, 2014. Disponível em: 〈http://www3.funceme.br/qualigraf>. Acesso em: 02 jul. 2016.

HINDI, E. C. et al. Os aquíferos contribuem no abastecimento da cidade de Curitiba-Paraná. Ver. Águas, subterrâneas nº 16, 2002.

IBGE. Pesquisa Nacional de Saneamento Básico, 2000.

INSTITUTO DAS ÁGUAS. Secretaria de Estado de Meio Ambiente e Recursos Hídricos. Diagnóstico das disponibilidades hídricas subterrâneas -parte B. Curitiba, 2010.

INVERNIZZI, A.L. Caracterização hidrogeoquímica do Aquífero Botucatu, no setor médio da bacia hidrográfica Mogi-pardo. Dissertação de mestrado - Programa de Pós-graduação em Geoquímica e Geotectônica. USP, São Paulo, 2001.

MACHADO, J. L. F. Água subterrânea: uma visão histórica. In: SIMPÓSIO BRASILEIRO DE RECURSOS HÍDRICOS, 16, 2005, João Pessoa. [Trabalhos apresentados]. João Pessoa: ABRH, 2005.

MINISTÉRIO DO MEIO AMBIENTE. Águas Subterrâneas: um recurso a ser conhecido e protegido. Associação Brasileira de águas subterrâneas. Brasília, 2007.

NETTO, J. P. G. M. et al. A ocorrência de fluoreto na água de poços da região metropolitana de São Paulo e novas tecnologias para sua remoção. XIII Congresso Brasileiro de Águas Subterrâneas, 2004.

OLIVEIRA, D. A. et al. Avaliação do teor de ferro em águas subterrâneas de alguns poços tubulares, no plano diretor de Palmas - TO. Universidade Federal do Tocantins (UFT), 2003. 
PINTO-COELHO, R.M.; HAVENS, K. Crise nas Águas. Educação, ciência e governança, juntas, evitando conflitos gerados por escassez e perda da qualidade das águas. Belo Horizonte: [s.n.], $2015,162 p$.

QUEIROZ, E.T. Diagnóstico de águas minerais e potáveis de mesa do Brasil. In: Anais...Congresso Brasileiro De Águas Subterrâneas, 13., Cuiabá, 2004. Cuiabá: ABAS, 2004.

SILVA, G.M.F. da.; CELLIGOI, A.; PINESE, J.P.P. Análise das águas dos poços de abastecimento público na bacia do Rio Pirapó através dos diagramas de Piper e Stiff. Revista Geografia (Londrina), v. 20, n.1, p. 11-128, 2011. 